\title{
Nietzsche on conscious and unconscious thought
}

\author{
Christopher Fowles, University of Oxford
}

\begin{abstract}
While much recent attention has been directed towards Nietzsche's reflections on the mind, and on consciousness in particular, his often-suggestive comments about thinking have thus far avoided comparable scrutiny. Starting from Nietzsche's claims that we "think constantly, but [do] not know it", and that only our conscious thinking "takes place in words" (GS \$354), I draw out the distinct strands that underpin such remarks. The opening half of the paper focuses upon Nietzsche's understanding of unconscious thinking, and the role of affects therein. In what remains, I consider the difference (for Nietzsche) between conscious and unconscious thought, with a particular focus on two important readings. The first, put forward by Paul Katsafanas, claims that conscious states alone have conceptually-articulated content. The second, defended most prominently by Mattia Riccardi, argues that Nietzsche's various claims evince a form of HOT theory. I argue that neither reading is quite right, and instead propose an alternative interpretation of conscious thinking "in words", which draws on work on inner speech.
\end{abstract}

\section{INTRODUCTION}

As Nietzsche's only extended discussion of consciousness in the published works, \354 of The Gay Science has attracted considerable attention from those looking to reconstruct his view of the mind. ${ }^{1}$ It is rarely noted, however, that in addition to the claims about consciousness and communication found therein, the passage also contains a number of suggestive remarks about thinking. Nietzsche writes that "man, like every living creature, thinks constantly, but does not know it", and that we could indeed "think, feel, will, remember, and also 'act' in every sense of the term", without any of this having "to 'enter our consciousness"'. The thinking that does become conscious, we are told,

\footnotetext{
${ }^{1}$ See Katsafanas (2005; 2016); Riccardi (forthcoming; 2015); Constâncio (2011).
} 
is but "the smallest part". It is this conscious thinking alone, Nietzsche claims, that "takes place in words" (GS \$354). ${ }^{2}$

Nietzsche evidently had some considered views on thinking, albeit elusive ones. My aim here is to tease out the positions that underpin such claims, and reconstruct Nietzsche's reflections on thought. Such an endeavour has bearing not only on the interpretation of GS $₫ 354$, but also on debates about his views on agency, deliberation, and consciousness more broadly. This task, however, is not without its challenges. Nietzsche's remarks on thinking are sometimes inchoate or incomplete, and many of the more substantial discussions are to be found in the Nacblaß. My intention, though, is not to ascribe to Nietzsche a fully worked-out, systematic account of cognition. Instead, I wish to argue that strands present in the published works or traceable from the Nachlaß to his published writings offer means of understanding the comments on thought in GS \$354. I hope to demonstrate that, despite being broad in its brushstrokes, the resultant picture is philosophically interesting.

I begin by clarifying which sorts of thinking concern us, before moving to Nietzsche's remarks on unconscious thought $(\$ 1)$. I highlight three facets of his picture of unconscious cognition: imagistic thinking (\$2.1); interpretive, analogical thinking (\$2.2); and the pervasiveness of affects $(\$ 2.3)$. The subsequent section of the paper addresses conscious thought, and the relationship between conscious and unconscious thinking (\$3). Therein, I consider the interpretations of Paul Katsafanas (\$3.1) and Mattia Riccardi (\$3.2), arguing that neither succeeds in characterizing Nietzsche's understanding of conscious thinking. In response, I propose an alternative view $(\$ 4)$, which draws on contemporary work on inner speech.

$\$ 1$.

Nietzsche's writings on thought convey a view both permissive and pluralistic. By this, I mean that he applies 'thinking'-language to phenomena that would not normally be considered in such terms, and that he uses 'thinking' to denote several different things. Our focus will be the thought that occurs "constantly" without our knowing, and the thought that "takes place in words". The former

\footnotetext{
2 Nietzsche's writings are cited using the abbreviations listed in the bibliography, according to book, essay (where applicable), and section. Nachlaß citations are to $\mathrm{eKGWB}$, year, book, section/fragment number. Translations from the Nachlaß are my own. (Emphases in original, unless stated.)
} 
of these I shall label unconscious-thinking, and the latter conscious-thinking. ${ }^{3}$ We shall return to consciousthinking later on. Let's start with unconscious thought.

In GS \$354, Nietzsche suggests not only that we could “think, feel, will, remember” without being conscious of it, but that "the predominant part" of our "thinking, feeling, and willing lives" takes place "without this mirroring". The passage offers little regarding the nature of this thinking, beyond the claims that it can occur unconsciously and will not take place "in words". Unfortunately, this doesn't get us far. Thinking "in words" might refer to the explicit articulation of the content of one's mental state in natural language. This would be compatible with that thinking not articulated explicitly in language nevertheless involving language-like vehicles. Alternatively, thinking "in words" might concern these vehicles, and thus the structure of the thought-processes themselves. The claim would then be that conscious-thinking alone involves the language-like representational format required for thought-processes to operate along logical relations between contents - making conscious-thinking markedly different from its unconscious counterpart. ${ }^{4}$

Consequently, GS $\$ 354$ tells us less about unconscious-thinking than we might have hoped. If we look elsewhere, Nietzsche's remarks suggest a considerable difference between unconscious thought-processes and our picture of conscious thinking. This requires some unpacking. Nietzsche contends that introspection presents only fragmentary evidence from which to construct an account of thinking, with deleterious consequences. The "logical thinking of which logic speaks", clarified as "a thinking where the thought itself is posited as the cause of new thoughts", is claimed to be "the pattern of a complete fiction: a kind of thinking which, in reality, never occurs" (eKGWB: 1885, 38, [2]; cf. eKGWB: 1885, 34, [249]). This is because the inferences, etc., presented as articulations of the thought-process are reconstructed entirely from conscious thoughts, providing no account of the unconscious operations between said thoughts. It is, he writes elsewhere, "only apparent that a thought would directly cause another thought. The events which are actually linked

\footnotetext{
${ }^{3}$ Nietzsche applies 'thinking'-language to four distinct phenomena. In addition to the conscious- and unconscious- thinking discussed here, we also find what we could call function-thinking and subject-thinking. The former concerns Nietzsche's extension of 'thinking'-language to what would normally be considered physiological functions (Z I, \$4; eKGWB: 1883, 24, [16]; 1884, 25, [403]). The latter denotes thinking understood as the activity of a substantive mental subject, distinct from its token mental states (BGE $₫ 17$; $\$ 54)$, something Nietzsche considered a fiction (eKGWB: 1887, 11, [113]; 1888, 14, [122]).

${ }^{4}$ These construals are, of course, not mutually exclusive.
} 
play out beneath our consciousness: the emerging sequence and one-after-the-other of feelings, thoughts, etc., are symptoms of the actual event!" (eKGWB: 1885, 1, [61]).

Nietzsche's suggestions about this "actual event" are, prima facie, puzzling. He insists elsewhere that a 'logical process, of the kind we 'find in a book', never occurs [...] Our thinking works fundamentally differently: between a thought and the next, an in-between world of entirely another kind prevails". The only hint provided regarding this "in-between world" is mention of "the drive to contradiction, or to subjugation, etc.” (eKGWB: 1885, 34, [170]). Plausibly, this opaque remark relates to a theme ubiquitous in Nietzsche's published and unpublished writings. He claims in The Gay Science, for example, that the "course of logical thoughts and inferences" actually "corresponds to a process and a struggle of drives that, taken separately, are all very illogical and unjust", and that "we usually experience only the result of the struggle" (GS $\$ 111$ - italics added). In the later works, he writes that "thinking is only a behaviour of [the] drives towards one another" (BGE §36), and, in a passage that takes a remark of Spinoza's as its starting point, of "intelligere" (understanding) as "a certain behaviour of the drives towards one another" (GS \$333). Similar claims abound in the Nachlaß. Thoughts, we are told, are "not the inner events themselves", but a "sign-language for the power-balance of the affects" (eKGWB: 1885, 1, [28]; cf. 1885, 1, [75]). In the passage where Nietzsche describes thoughts, etc., as "symptoms of the actual event", he writes that beneath every thought "lies an affect": "Each thought, each feeling, each will", he writes, "is born not of a specific drive, but is a total state, a whole surface of the entirety of consciousness, and results from the ascertainment of the power of all our constituent drives in that instant [...] The next thought is a sign of how the entire power-situation has shifted in the meantime" (eKGWB: 1885, 1, [61]). ${ }^{5}$

As we saw, our cognition is radically different to the logical thought "of which logic speaks" (eKGWB: 1885, 38, [2]) because such formalizations are simplified reconstructions of thinkingprocesses, abstracted from patterns of conscious thoughts. On the view here presented, the "events which are actually linked" that "play out beneath our consciousness" (eKGWB: 1885, 1, [61]) operate not through a succession of language-like representations, following rules of inference, etc., but (at least partly) through a struggle between drives and/or affects, ${ }^{6}$ of which we

\footnotetext{
${ }^{5}$ Constâncio (2011) contains an interesting discussion of this passage.

${ }^{6}$ Nietzsche appears to use 'drive' and 'affect' interchangeably in regard to thinking. For the sake of simplicity, I will talk of 'affects' henceforth.
} 
experience only the result. It's one thing to suggest that Nietzsche held this view, however, and quite another to explain what it means, and how it could represent a plausible or interesting conception of thinking. His comments offer a mixture of clearly-stated, even precise, claims, with some suggestive-if-rather-inchoate ones. It is to drawing out this picture that we now move.

$\$ 2$

The first step in unpacking Nietzsche's affect-thinking concerns affects themselves. Since we have insufficient room for an extensive examination of his view of affective states, ${ }^{7}$ I wish to highlight two (reasonably uncontroversial) features: first, that Nietzsche understands occurrent affects as responses to stimuli; and second, that he takes such states to modify certain psychological processes. With these in mind, I'm going to make three claims which hopefully add flesh to the bare bones laid out thus far. The first is that affect-thinking is imagistic; the second, that it involves interpreting and a form of analogical thinking; and the third, that it is the constant presence of affects that properly explains the putatively unabating nature of thought. Let's take these in turn.

It is often claimed that the format of representations utilized in thinking-processes must be language-like. Nevertheless, recent work (some of which aims at providing a compelling account of animal cognition) has emphasized the forms of thinking possible through an image-like representational format. While Nietzsche clearly lacked such terminology, his writings reflect a sensitivity to the idea of imagistic thinking. In several early Nachlaß passages on 'unconscious inferences, ${ }^{8}$ he writes that they "arouse [his] doubts", suggesting instead that the process "will arguably be the passing from image to image". This "image-thinking [Bilderdenken]" is purportedly not of a "strictly logical nature, but is still more or less logical". By contrast, philosophers endeavour "to set conceptual-thinking [Begriffsdenken] in the place of image-thinking" (eKGWB: 1872, 19, [107]; cf. 1872, 19, [217]). Another note on image-thinking from the same year elaborates: Nietzsche writes, "the intellect rapidly chooses similar images: the chosen one generates a whole

\footnotetext{
${ }^{7}$ For a fuller discussion of Nietzsche's view of affects, see Fowles (forthcoming).

8 The term was coined by Hermann von Helmholtz (1867).
} 
plethora of images once more: quickly, however, it chooses one from this again, etc." (eKGWB: $1872,19,[78])$.

Instead of thinking understood as operating along logical relations between linguisticallystructured contents, Nietzsche proposes a form of non-linguistic thinking which works on imagistic vehicles. In this respect, his position hardly changes. He writes in 1881 that "imagination is to be posited in the place of the 'unconscious': they are not unconscious inferences, but rather possibilities thrown out, provided by the imagination" (eKGWB: 1881, 11, [13]); and two years later of "how thoughts are only images, how words are only signs of thoughts" (eKGWB: 1883, 24, [16]). If we return briefly to the early notes, Nietzsche relates image-thinking to drives. Having passed from "image to image", the final representation upon which the intellect settles "acts as a stimulus and motive": the "instincts", he writes, "also appear to be such an image-thinking, that finally becomes stimulus and motive" (eKGWB: 1872, 19, [107]).

We can trace this through to the mature work. In a passage redolent of the early notes, Nietzsche suggests that purposes, which "usually [occur] in the brain only after everything has been prepared for [their] execution" are "an 'inner' 'stimulus' - no more" (eKGWB: 1883, 24, [34]). Elsewhere, he asks, "why could 'a purpose' not be an epiphenomenon in the series of changes in the forces that bring about purposive action - a pale sign-image [Zeichenbild] thrown into consciousness beforehand, that serves to orientate us concerning what is happening, even as a symptom of events, not as their cause?” (eKGWB: 1886, 7, [1]). Twelve months later, in the fifth book of The Gay Science, Nietzsche discusses two "kinds of causes that are often confused", distinguishing between the "cause of acting" and the "cause of acting in a certain way, in a certain direction, with a certain goal". Among the latter class, he places "so-called "purposes", which he countenances could be "a beautifying pretext, a self-deception of vanity after the fact" (GS \$360).

Of course, this doesn't entail that all purposes are imagistic. Nevertheless, Nietzsche likely took imagistic thinking to be at least part of the process that has purposes as its output, and often the entirety. On his view, the "imagination", stimulated by sensory information, produces a rapid succession of images, culminating in a final "sign-image" - a mental representation of the state of affairs to be brought about (or avoided) through action, identified consciously as the 'purpose' of acting. The "represented goal of action", Nietzsche suggests, "provides an anticipation of release, and thereby stimulates discharge ever further", with the "subsequent action" providing the "actual release": in the process, the "doer forgets the actual driving force and sees only the "motive"" (eKGWB: 
1883, 7, [77]; cf. D \$129). So understood, our conception of action is distorted by the range of evidence to which we have introspective access. The 'purpose' is itself the result of a complex process, and serves to stimulate further affects and orientate subsequent action.

Although these remarks fall short of an account of imagistic thought, they offer a sketch of the interaction of imagistic representations and affects to fit into our reconstruction of Nietzsche's unconscious-thinking. As it stands, however, this is a somewhat thin picture of non-linguistic cognition tout court. Happily, there is more we can draw from Nietzsche's writings. His remarks on interpretation, in particular, render his view of unconscious-thinking more substantial. Nietzsche discusses interpreting both in relation to drives and affects. Such interpretation will plausibly involve, inter alia, the generation of perceptual saliences (Katsafanas, 2013: 740). Nietzsche's remarks suggest something similar to affordance perception (Gibson 1977; 1979). Objects, events, and people afford different behaviours, interactions, and opportunities: a handle affords the opportunity to grab; a door, the opportunity to exit. A drive which "desires gratification", Nietzsche suggests, regards "every event of the day with a view to seeing how it can employ it for the attainment of its goal" (D \$119; cf. eKGWB: 1885, 1, [58]). Drives make salient features of the environment, and the opportunities, interactions, etc., the environment affords, through which one's state can be discharged.

Nietzsche arguably has a similar view in mind for affects: "interpreting", he writes, "has existence (but not as a "being", rather as a process, a becoming) as an affect" (eKGWB: 1885, 2, [151]). Drives and affects can be said to have their own perspective, from which sensation is interpreted and evaluated. Elements of one's surroundings are valenced as objects of inclination or aversion, and ascribed a meaning/function from the practical perspective of one's state. In a late note, Nietzsche sketches the sort of process he envisages. The "origin" of pleasure and displeasure, he writes, "is in the central-sphere of the intellect": their "pre-condition is an infinitely accelerated perceiving, ordering, subsuming, recalculating, inferring". Feelings of pleasure and displeasure, described as "will-reactions (affects)", presuppose a "measuring regarding overall benefit, overall harmfulness: thus, a sphere where the willing of a target (state) and a selection of the means takes place" (eKGWB: 1887, 11, [71]). This clearly resonates with the discussion of 'purposes' in $\$ 2.1$ a. So understood, interaction with the environment is dynamic and affect-guided, in response to an ever-updating assessment of one's surroundings. 
The above process seems plausibly to instantiate a form of non-linguistic thinking called analogical thinking. This refers not to an explicit, conscious connection of ideas or situations, but to the perception of analogies between them (Bermúdez, 2003: 36). In such instances, one sees something as saliently similar to a previously experienced thing, and can bring one's knowhow to bear upon it. Something along these lines emerges from Nietzsche's remarks on the psychological mechanism that extracts putative causes for occurrent state(s) from one's surroundings, the most prominent discussion of which can be found in Twilight of the Idols. ${ }^{9}$ Nietzsche writes therein that "[m]ost of our general feelings - every sort of restraint, pressure, tension, explosion in the play and counterplay of our organs, [and] the condition of the nervus sympathicus" all "excite our cause-drive". Memory, which "becomes active without our being aware of it", then draws up "earlier states of a similar kind, and the causal interpretations that have grown out of them". In time, there "arises a babituation to a certain causal interpretation" (TI VI, \$4), the deployment of which, as something "already known, experienced, inscribed in memory", has a palliative effect (TI VI, \$5).

Naturally, many of these aetiologies will be linguistically-articulated and theory-laden, such that it would be implausible to ascribe them to non-linguistic creatures. Nevertheless, Nietzsche attributes a degree of fundamentality to the referral of sensation to putative cause, sufficient to render unlikely the suggestion that it occurs only in language-using creatures (cf. eKGWB: 1888, 15, [90]; 1885, 34, [54]). The connection of event and state is grounded in experience (eKGWB: 1883, 24, [20]; 1880, 1, [115]; TI VI, \5), and the process of identifying circumstances as those for which a particular explanation is apposite appears to rely more upon association, proceduralization, and patternrecognition than linguistically-mediated reasoning.

Recognizing that the struggle of affects involves competing practical-evaluative perspectives, with different features and affordances rendered salient from each, provides insight into how a fluctuating “power-situation" involving "all our constituent drives" (eKGWB: 1885, 1, [61]) could be partly constitutive of thinking. There remains, however, a final element of Nietzsche's affectdriven unconscious-thinking to highlight, related to his claim in GS \$354 that we think "constantly, but [do] not know it". In Daybreak, Nietzsche writes that words "exist only for superlative degrees

\footnotetext{
${ }^{9}$ Cf. HAH I, \13; D \$119; eKGWB: 1883, 24, [20]; 1884, 26, [92]; 1885, 38, [1]; 1888, 15, [90]. For discussion, see Fowles (forthcoming).
} 
[of] drives and processes", claiming that we "are none of us that which we appear to be in accordance with the states for which alone we have consciousness and words". We "misunderstand ourselves", he writes, on the basis of these "cruder outbursts", as we "draw a conclusion on the basis of data in which the exceptions outweigh the rule". Those instances of which we become conscious are actually "extreme states": the "milder, middle degrees, not to speak of the lower degrees [of "drives and processes"] elude us", but are nevertheless “continually in play" (D \$115).

The best explanation of Nietzsche's suggestion that thinking occurs "constantly" is that he takes the interaction of affects to be partially constitutive of unconscious-thinking, and takes affects to be near-constant features of mental life. In this regard, Nietzsche's view arguably foreshadows elements of Antonio Damasio's account of practical reasoning. Damasio suggests that when making decisions, we entertain representations of the available options: the "key components", he claims, "unfold in our minds instantly, sketchily, and virtually simultaneously, too fast for the details to be clearly defined". Instead of engaging in lengthy conscious deliberation, when "the bad outcome connected with a given response option comes into mind, however fleetingly, you experience an unpleasant gut feeling” (1994: 173). Emotions act as a sounding-board for the contents of consciousness, marking various options with positively or negatively valenced feeling. Accordingly, for Damasio, they play an essential role in certain rational behaviours, and a far more pervasive role than commonly assumed.

Although Nietzsche's picture is occasionally underdeveloped, and less systematic than Damasio's, the broad-brushstrokes of each are remarkably congruent. As Damasio envisages processing unfolding "instantly, sketchily", etc., with emotions marking represented options, Nietzsche talks of the "represented goal of action" providing "anticipation of release" (eKGWB: 1883, 7, [77]), and of an "infinitely accelerated perceiving, organizing, subsuming, recalculating, concluding" with valenced "will-reactions (affects)" as outputs (eKGWB: 1887, 11, [71]). Redolent of the "milder" states Nietzsche discusses, which abound between "superlative" instances, Damasio writes of "background feelings" that correspond to the "body state prevailing between emotions", which are "neither too positive nor too negative". Such feelings are "perceived as mostly pleasant or unpleasant", and, he suggests, likely contribute to moods (1994: 150-151). Both present affective states as ebbing and flowing, responsive to the images, 'purposes', and thoughts that become conscious. For Nietzsche, this process is effectively constant. Those affects strongest at a given time dominate the intellect, stimulating and modifying psychological processes. They have at their disposal the imagination and memory, as well as the causal interpretations, etc., built up through experience. These dominant 
affects determine one's evaluative perspective and the affordances experienced as salient, and in doing so determine the patterns of activity pursued.

$\int 3$.

Nietzsche's suggestions regarding unconscious-thinking, although clearly in need of precisification and development, anticipate recent work on non-linguistic thought. In perhaps the most extensive treatment of the topic, José Luis Bermúdez discusses imagistic and analogical reasoning as examples of forms of thought that don't rely on linguistic vehicles (2003: 36). Bermúdez also distinguishes between what he calls thinking-that and thinking-how (analogous to Gilbert Ryle's distinction between knowing-that and knowing-how). Paradigmatic cases of thinking-bow have several things in common. First, they could be described as skills (as opposed to bodies of knowledge). They are, more precisely, skills "that allow one to modify and adjust oneself to the environment" (2003: 36). For this reason, Bermúdez emphasizes the importance of affordance to any account of thinking-bow (2003: 47). Second, in cases of thinking-bow, the thought processes themselves "cannot easily, if at all, be put into words". While one can naturally describe features of one's mental states or articulate conclusions, etc., we can't "express in language the thinking that leads up to that conclusion" (2016: 37). These remarks chime with Nietzsche's insistence that unconscious-thinking "works fundamentally differently" (eKGWB: 1885, 34, [170]) to conscious thought. We are, however, capable not just of thinking-how, but also thinking-that - of which Nietzsche's conscious-thinking, which "takes place in words", is presumably a paradigm. How should we understand the relationship between conscious- and unconscious-thinking? And what does it mean for conscious-thinking to "take place in words"? In what follows, I shall consider two influential answers to these questions, neither of which, I contend, is entirely successful.

\section{$\$ 3.1$}

In a number of sophisticated pieces on Nietzsche's view of the mind, Paul Katsafanas has argued that Nietzsche connects consciousness to conceptualization. Katsafanas suggests that the correct way to understand the claim that conscious-thinking takes place "in words" is as the claim that only conscious mental states have conceptual content (2016: 26). The argument for this conclusion involves four moves:

(i) Conscious thinking alone takes place in words (GS \$354). 
(ii) There can be no words without concepts: words are "acoustic signs for concepts" (BGE \268), meaning “words express or signify concepts” (Katsafanas, 2016: 25).

(iii) To think in words "is to think by means of concepts" (2016: 25-6) - i.e., consciousthinking is conceptually-articulated. (from (i) and (ii).)

(iv) There can be no concepts, however, without words: concepts are "possible", Nietzsche writes, "only once there are words" (eKGWB: 1884, 11, [25]).

(c) Therefore: only conscious states have conceptual content. (from (iii) and (iv).)

On Katsafanas' reading, only conscious-thinking is conceptually-articulated: unconscious-thinking becomes conscious-thinking through its content being conceptualized. The case for his conclusion is detailed and often insightful. Despite this, I doubt this is the correct way to understand consciousthinking occurring "in words". In the above argument, (i)-(iii) seem reasonably unproblematic. The key stage is (iv). It is this that binds words and concepts sufficiently closely to support Katsafanas' reading of GS \$354, allowing him to move from the uncontroversial statement that consciousthinking is conceptually-articulated for Nietzsche, to the more contentious claim that conscious content alone is conceptual. My concern is that there are different construals of (iv) that Katsafanas fails to separate. One relates to linguistic ability, the other to linguistic articulation. Once held apart, neither provides compelling support for reading Nietzsche's remarks about thinking "in words" in terms of conscious states alone involving concepts. Or so I shall argue.

$\S 3.1 \mathrm{a}$

What might Nietzsche mean in suggesting that there are concepts "only once there are words"? One could read this as the claim that mental states can have conceptual content, only if their content is articulated in natural language. Words, so understood, would be the sole vehicle for conceptual content. This is the articulation reading of (iv). Alternatively, one could understand Nietzsche's remark as the claim that words are necessary for concept possession - i.e., only once we possess language can we possess concepts. On this ability reading, only linguistic creatures would be able to have mental states with conceptual content.

Plausibly, Katsafanas must accept the ability reading. The articulation reading resembles the view Katsafanas ascribes to Schopenhauer, which he claims Nietzsche rejects. Contra Schopenhauer, Nietzsche, it is argued, takes conscious perceptual states to have conceptual content. "Perceptual content", Katsafanas writes, "would be conceptual if the perceived object were represented as an instance of some concept, that is, as a token of some type" (2016: 32). This is purportedly what 
we find in BGE \$192, where Nietzsche describes something like categorical perception. Perceptual processing, as Nietzsche envisages it, putatively alters the content of perception, such that it is adequately specifiable in terms of concepts the perceiver possesses. Despite lacking explicitly linguistically-articulated content, perceptual states would thus represent objects as "instance[s] of some concept" (2016: 32). If correct, this rules out the articulation reading.

The ability reading, however, meets its own difficulties. Consider the suggestion that Nietzsche thought linguistic competence necessary for concept possession. Katsafanas argues that for Nietzsche, mere discrimination does not suffice: concept possession is also a matter of "understanding the concept's place in [a] system of relations" (2016: 25); of being able to employ it (alongside other concepts) in thought and communication (2016: 36-7); and of being able to use it in abstract thought, without the thing in question being perceptually (or imaginatively) present (2016: 36). Since these plausibly require linguistic competence, it follows that one can only possess a concept if one has mastery of a language.

Yet, substantial textual support for these claims is not forthcoming. Regarding the suggestion that concept possession requires appreciation of a concept's place in a broader scheme, Katsafanas mentions that Nietzsche often links concepts to schema (2016: 35, n. 30). Katsafanas points to BGE $\$ 20$, where Nietzsche writes that "individual philosophical concepts are not arbitrary, do not grow up on their own, but in connection and relationship with each other", and remarks on "the innate systematicity and relationship of concepts". This is all well and good - Nietzsche does link concepts to schemas with great regularity. But it remains unclear why such remarks should be taken to issue a condition for concept possession. ${ }^{10}$

The further requirements, relating to communication and abstract thought, fare no better. Katsafanas highlights BGE $\$ 268$, where Nietzsche insists that using "the same words is not enough to ensure mutual understanding", stressing the need for shared experiences if people are to make themselves understood quickly and easily. Nietzsche's point, however, seems to be that communication requires that individuals "use the same words for the same categories of inner experience” (BGE \$268). The individuals in question might employ the same words, and already possess categorical abilities (with corresponding terms). The issue is the possibility of the same

10 The same can be said of On Truth and Lies in the Extra-Moral Sense, which Katsafanas also mentions (2016: 25, n. 17). 
words corresponding to different categories in different people, resulting in failures to understand one another. While this suggests a condition on successful communication, it is not obvious that Nietzsche intends these remarks to highlight a condition on possessing the categorical, classificatory ability in the first place.

A more serious concern is that if Nietzsche ties concepts to linguistic ability, the bind is plausibly not tight enough for Katsafanas' purposes. The ability reading falls short of establishing that only conscious states are conceptually-articulated. While it provides a way in which conscious perceptual states could be said to have conceptual content, it does so at the cost of undercutting the motivation for the claim that unconscious states could not. Even if successful, Katsafanas' arguments would only demonstrate that linguistic creatures alone could have conceptually-articulated mental states - not that only the conscious states of these creatures would have conceptual content. This leaves open the possibility that the unconscious-thinking of language-possessing creatures might well involve contents that represent objects as "token[s] of some type".

So what about the articulation reading? Although incompatible with the conclusion that all conscious states have conceptual content, might it not offer the correct account of the distinction between conscious- and unconscious-thinking? If words are the only vehicles for conceptual content, Nietzsche's claim that conscious thinking alone takes place in words would entail that unconscious states lacked conceptual content. As mentioned earlier, the articulation reading is close to Schopenhauer's view, which surely influenced Nietzsche's thinking regarding consciousness and concepts (as Katsafanas rightly claims). The problem with the articulation reading is that there are textual reasons to be cautious about ascribing the view to the mature Nietzsche. There are clearly Schopenhauerian overtones to some of the younger Nietzsche's writings on thought. As we saw, he contrasts "imagethinking" with "concept-thinking", lamenting philosophers' efforts to account for everything in terms of the latter. Nietzsche insists, in the same passage, that "Unconscious thinking must take place without concepts: thus, in intuitions [Anschanungen]" (eKGWB: 1872, 19, [107]). If we look to On Truth and Lies in the Extra-Moral Sense (which Katsafanas mentions), Nietzsche claims therein that "Every word immediately becomes a concept".

The passage from which (iv) is derived has a not-dissimilar feel: "First images [...] Then words, applied to images. Lastly, concepts, possible only when there are words - a summarizing of many images under something not clear, but audible (word)" (eKGWB: 1884, 25, [168]). The structure of 
Nietzsche's view changes little over time. Brute sensation is reconstructed with the aid of "imagination" or "memory", utilizing "images", "forms", or "signs" - recognitional templates developed through abstraction from particular experiences. ${ }^{11}$ Linguistic ability then facilitates the communication of the content of our experiences. The issue for the articulation reading is that Nietzsche's views appear to change regarding which of the above components should be considered 'concepts'. The greatest concentration of writings on both thinking and concepts occurs between the latter parts of 1884 and the early stages of 1886. Here, the Schopenhauerian emphasis on the importance of words to the development of concepts disappears. The thought expressed in the Nacblaß passage quoted by Katsafanas (from Spring 1884) never surfaces in the published works, nor (to my knowledge) does it re-appear in the notebooks. ${ }^{12}$

By the second half of 1884, Nietzsche's view seems to have shifted. He writes that one "must relearn about memory": it is the "multitude of all the experiences of all organic life [...] simplifying, grouping together, and transforming into many unities. There must be an inner process that behaves as the concept-formation from many individual cases" (eKGWB: 1884, 26, [94]). In mid-1885, Nietzsche writes of signs as essential to memory, referring in particular to Zeichenschrift (eKGWB: 1885, 34, [249]), an image-like symbol. Around this time, the ideas that become BGE $\$ 268$ emerge. Nietzsche writes that "Words are acoustic-signs for concepts: concepts, however, are more or less secure groups of recurring sensations that appear together" (eKGWB: 1885, 34, [86]), and that “concepts are signs for recognition” (eKGWB: 1885, 1, [50]). When this surfaces in BGE $\$ 268$, the line is that "Words are acoustic-signs for concepts; concepts, though, are more or less determinate image-signs for sensations that occur together and recur frequently, for groups of sensations" - entirely in keeping with the development of his view over the preceding 18 months.

Concept-formation is presented in these passages as a process of developing image-like signs through repeated experience, which then facilitate recognition. As Mattia Riccardi has helpfully noted (Riccardi, forthcoming), Nietzsche’s remarks in BGE \$268 resemble David Papineau's discussion of sensory templates. Papineau in fact posits not only perceptual concepts (the

\footnotetext{
${ }^{11}$ See GS \114; BGE \192; eKGWB: 1872, 19, [217]; 1881, 11, [13]; 1884, 26, [94].

12 A note from Autumn 1884-Spring 1885 comes closest. Nietzsche mentions "primitive humans" communicating with signs: "First signs", he suggests, "then concepts, finally 'reason' in the customary sense" (eKGWB: 1884, 30, [10]). This is at best ambiguous, however, since Nietzsche considered gestures to be signs/symbols (HAH, $\$ 216$; eKGWB: 1885, 1, [28]).
} 
templates themselves), but also perceptually-derived concepts (Papineau, 2006: 118). These can be employed in thought, in the absence (perceptually or imaginatively) of the thing to which the concept corresponds. For this class of concepts, Papineau countenances that language might well be necessary (Papineau, 2006: 119). This is redolent of the form of Nietzsche's view throughout his life, where templates are employed to structure the content of experience. In Nietzsche's earlier writings, plausibly under Schopenhauer's influence, this structure is considered to be nonconceptual: it is only what Papineau identifies as "perceptually-derived" concepts that constitute concepts proper (hence Nietzsche's focus on language). Over an extended period of reflection on thinking and concepts, however, Nietzsche's view moves closer to Papineau's, with the templates themselves considered to be (perceptual) concepts.

If this is correct, we should resist the idea that the distinction between conscious- and unconsciousthinking maps onto the conceptual/nonconceptual distinction. The ability reading extends conceptualization beyond states with linguistically-articulated content, but in doing so fails to secure a sufficiently close bind between concepts and consciousness to support Katsafanas' conclusion. The link between concepts and consciousness is tighter on the articulation reading, but the view lacks textual warrant. Given Nietzsche's remarks, pace Katsafanas, the unconscious-thinking we discussed earlier could indeed involve concepts. Whatever Nietzsche is getting at in suggesting that conscious-thinking alone "takes place in words", it is not, I submit, that it alone is conceptuallyarticulated.

In this section, we consider an alternative interpretation, on which it is argued that Nietzsche's remarks suggest an actualist form of higher-order thought (HOT) theory. ${ }^{13}$ On such HOT theories, consciousness of a state or content is explicated in terms of the state/content being the target of an occurrent HOT (Rosenthal, 2005: 21-45). The most extensive discussions of the HOT view in regard to Nietzsche can be found in the work of Mattia Riccardi, upon which I will focus here. Riccardi reads Nietzsche as a pluralist about consciousness, meaning that multiple forms of 'consciousness' appear in Nietzsche's writings. Riccardi distinguishes qualitative consciousness,

\footnotetext{
13 See Riccardi (forthcoming; 2015); Doyle (2011). Brian Leiter has also stressed the similarities between Nietzsche's views and the HOT theory ("Katsafanas on Nietzsche on Consciousness", Brian Leiter's Nietzsche Blog, May 1st, 2008. Last accessed on $26^{\text {th }}$ October 2017, at http:/ / brianleiternietzsche.blogspot.co.uk/2008/05/katsafanas-onnietzsche-on.html). For a different comparison between Nietzsche the HOT view, see Katsafanas (2016: 41-44).
} 
perceptual consciousness, and a dominant sense of consciousness ( ${ }^{\mathrm{D}}$ consciousness) which he suggests is self-consciousness. It is ${ }^{\mathrm{D}}$ consciousness that is claimed to operate "according to a HOT model" (2015: $6)$.

Riccardi's argument starts with Nietzsche's remark that consciousness is "the represented representation, the represented will, the represented feeling (with which we alone are acquainted)" (eKGWB: 1884, 26, [49]), which he plausibly takes as evidence that Nietzsche holds some form of higher-order representation (HOR) account. But which one? Riccardi draws our attention to the fact that Nietzsche equates man's need for consciousness with a need “to 'know' what distressed him, to 'know' how he felt, to 'know' what he thought” (GS \$354). This, Riccardi claims, suggests that "for a certain mental state $\mathrm{M}$ to be ${ }^{\mathrm{D}}$ conscious it is required that $\mathrm{M}$ be the content of a HOT to the effect that I am in M” (2015: 6). In support, Riccardi highlights several similarities between Nietzsche's views and the work of David Rosenthal, the most prominent (actualist) HOT theorist (Riccardi, forthcoming: 6-7).

So understood, conscious-thinking is thinking targeted by a HOT. Riccardi suggests that the comments about thought in GS $\$ 354$ should be understood broadly, to include all attitudinal states: Nietzsche's position, he claims, "seems to be that all and only ${ }^{D}$ conscious mental contents are articulated propositionally" (2015: 6). The significance of language is thus partly owing to the fact that HOTs require a state to be "ascribed to a self", which requires that one possess linguistic competence sufficient for mastery of a "self-referential pronoun" (2015: 7). Riccardi makes several persuasive points. I agree that Nietzsche is a pluralist about consciousness, and that his writings bear some resemblance to Rosenthal's. Moreover, the idea that conscious-thinking is articulated in a manner different to unconscious-thinking comports with my earlier remarks about non-linguistic thought. Nevertheless, I have reservations about whether consciousness (as discussed in GS §354) works on a HOT model, and consequently whether the HOT reading captures what Nietzsche means by conscious-thinking taking place in words.

Advocates of full-blown actualist HOT theories (like Rosenthal) claim that a mental item is conscious iff it is the object of a HOT, whether we are talking about phenomenal consciousness of redness, or reflective awareness of one's own attitudes, etc. Riccardi sensibly distances his reading from more extravagant HOT views, and restricts his claim to self-consciousness (2015: 5-6). On this restricted view, "to be conscious of one's present state of knowing that $p$, one needs to have 
the HOT 'I think' about that $p$ ” (2015: 6). If we sketch a HOT model for propositional attitudes, we start with a first-order attitude towards a proposition, e.g., knowing: [(that $p)]$. This is presently unconscious, becoming conscious only when targeted by a HOT. This unconscious higher-order thinking would involve a new proposition, i.e., thinking: [I KNOW (that $p$ )]. One could then express one's knowing that $p$ in speech or action.

There are reasons, however, to doubt that this was Nietzsche's view. For a start, as above, extant HOT theories posit unconscious, conceptually-articulated propositional thoughts at first-order and higher-order levels. If one reads Nietzsche's "in words" claim in terms of propositional (Riccardi) or conceptual (Katsafanas) articulation, Nietzsche's position would appear to diverge considerably from the particular HOT views to which his remarks have been compared. This is hardly decisive, however. More pressing concerns emerge if we attend to something like introspection. Should one wish to bring their "knowing that $p$ " to a point of conscious introspection on the HOT view, it requires an (unconscious) third-order thought, i.e., thinking: [I THINK I KNOW (that p)]..$^{14} \mathrm{~A}$ first worry is that it is deeply questionable whether the texts can support attributing this to Nietzsche. Although he talks of "represented representation[s]", and makes several references in this context to Leibniz (GS \$354; \$357) - who certainly did countenance a regress of thoughts (Leibniz, 1768/1981: 118) - this hardly constitutes a solid basis for ascribing to Nietzsche so intricate a position.

This suggests a far more significant divergence from extant HOT views. Nietzsche does envisage further cognitive operations in relation to conscious-thinking, as we shall see shortly. There is no suggestion, however, that this further cognition renders the second-order thinking conscious. Indeed, the simplest and most natural way to read Nietzsche's comments is as evincing a view on which linguistically-articulated conscious-thinking about one's own mental state is conscious without any further HOT making it so. If this is correct, even though Nietzsche's remarks bear resemblance to some claims HOT theorists make, his view strikes me as neither properly nor helpfully described as a HOT theory. Even on Riccardi's restricted reading, Nietzsche's position denies what could

\footnotetext{
${ }^{14}$ Cf. Rosenthal: Introspection "is the special case in which that [previously unconscious] HOT is conscious, which happens when a yet higher-order thought occurs - a third-order thought about the second-order thought" (2005: 113).
} 
plausibly be considered the central tenet of the HOT view - viz. that every conscious item (in a given domain) is conscious in virtue of being the target of a HOT. ${ }^{15}$

$\int 4$.

Nietzsche's picture clearly involves meta-representation - specifically, it involves thoughts about first-order mental states/contents. But this underdetermines the ascription of a HOT theory. I wish instead to sketch an alternative; one which hopefully retains the virtues of the HOT view without its baggage. Nietzsche's position, I contend, more closely resembles contemporary work linking consciousness to inner speech than it does standard HOT theories. The 'inner speech' claim is that conscious thinking occurs in imaged natural language sentences. ${ }^{16}$ Theorists focus most commonly upon articulation in inner speech, although there's no deep distinction between thinking to oneself and talking to oneself or others.

Nietzsche is remarkably consistent in linking consciousness explicitly to language. In Daybreak, for example, he writes, "where words are lacking, we are accustomed to abandon exact observation $[\ldots]$ in earlier times one involuntarily concluded that where the realm of words ceased the realm of existence ceased also" (D \$115). In the notebooks from the previous year, he claims that the "thought-image consists of words" (eKGWB: 1880, 6, [361]; cf. eKGWB: 1880, 6, [362]). A later passage on consciousness and communication (some of which would surface in GS \$354) touches upon how consciousness is "possible" - Nietzsche claims to be "far from coming up with answers", offering only: "words, and not more!" (eKGWB: 1884, 30, [10]). Around the time of the writing of GS $\$ 354$, we find him insisting that "we think only in the form of language": we "cease to think.", Nietzsche claims, "when we refuse to do so under linguistic constraint; we barely reach the doubt that sees this limitation as a limitation" (eKGWB: 1886, 5, [22]).

Such passages are most naturally read as linking conscious thinking to sentences articulated internally in natural language. As a reading of Nietzsche, this has several strengths, beyond simply fitting well with his remarks. It allows us, first of all, to take him at his word: conscious-thinking "takes place in words", and an inner speech reading offers a pleasingly straightforward sense in which that

\footnotetext{
15 Thanks to Mattia Riccardi and Reid Blackman for comments that helped make this section clearer.

16 See Ryle (1949: 176); Gauker (1994: 221); Carruthers (1996: 51); Bermúdez (2003: 159-160).
} 
is so. The meta-representational element of Nietzsche's view is also comfortably accommodated by the inner speech reading. The fact that we can represent our mental states/contents in natural languages sentences is incontestable.

There are also important similarities between Nietzsche's writings and those of theorists focussing upon the role of public language in cognition. Natural language has been implicated in facilitating further meta-cognition, rendering possible what Andy Clark calls "second-order cognitive dynamics". Once we "formulate a thought in words", Clark writes, "it becomes an object both for ourselves and for others. As an object it is the kind of thing we can have thoughts about". Contra the HOT view, in "creating the object we need have no thoughts about thoughts - but once it is there, the opportunity immediately exists" (1996: 177). This seems to be very much what Nietzsche has in mind. He writes that "the capacity to will, to feel, and to think something of our willing, feeling, thinking itself" is summarized "with the word "consciousness" (eKGWB: 1885, 34, [87]). For Nietzsche, as for Clark, natural language sentences act as stimuli for further unconscious processing. Nietzsche writes that in conscious thought, "everything expresses something of our total-state in signs", and that "for consciousness, each thought acts namely as a stimulant" (eKGWB: 1885, 38, [1]). Thoughts articulated in natural language provoke a further struggle of affects, with one's subsequent thoughts reflecting how the "entire power situation has shifted in the meantime" (eKGWB: 1885, 1, [61]).

Crucially, the inner speech reading avoids the difficulties of the HOT theory. This is because Nietzsche needn't commit to any particular account of what makes linguistically-articulated sentences like [I KNOW (that p)] conscious. Although he offers few suggestions regarding how non-linguistic thinking is pressed into public language, ${ }^{17}$ it is unclear that he would be obliged to. Nietzsche is engaged in speculative theorizing, and inner speech is an undeniable part of mental life. He can posit natural language sentences "silently uttered or entertained in thought" (Bermúdez, 2005: 281) without having to posit accompanying iterations of HOTs. If correct, reading Nietzsche as anticipating elements of modern inner speech views provides a means of understanding his

\footnotetext{
${ }^{17}$ In keeping with much I have said above, Nietzsche's comments suggest that we struggle to articulate the content of unconscious thinking in language. He writes (in a passage entitled "Thoughts and words") that one "cannot even reproduce one's thoughts in words entirely" (GS \$244); and asks elsewhere, "If there were an 'in itself at all, what, then, would be the 'in itself of a thought?" (eKGWB: 1885, 1, [74]). His view appears to be that conscious linguistic articulation fixes the content of a thought (for other cognitive processes to respond to). In Daybreak, for instance, he writes that we "always express our thoughts with the words that lie to hand. Or, to express my whole suspicion: we have at any moment only the thought for which we have to hand the words" (D \$257).
} 
various claims regarding consciousness and language which retains the virtues of the HOT view without its complications.

\section{CONCLUSION}

Nietzsche's remarks on thinking are apt to confuse. His notebooks reveal lengthy periods of reflection on the topic, which result in a handful of condensed, suggestive comments surfacing in the published works. Nietzsche's picture of unconscious-thinking, I have argued, grows from three distinct contentions: that unconscious-thinking utilizes imagistic vehicles; that it involves interpretation and analogical thinking; and that it is partly constituted by a "struggle" of affects. So understood, unconscious-thinking does not operate along relations between syntactic features of language-like constructions (as is suggested by logical reconstructions of the thought-process). I have also argued that in claiming conscious-thinking "takes place in words", Nietzsche has in mind neither conceptualization, nor something akin to the HOT theory. Instead, his position is closer to contemporary work on inner speech. We become conscious of thinking by representing it in imaged natural language sentences, which become the stimuli for further unconscious-thinking.

There is, of course, more to be said about Nietzsche's writings on thought. The above interpretation, if correct, brings Nietzsche's writings into contact with areas of contemporary research (e.g., non-linguistic thought) and bears in interesting and important ways on his views of motivation and agency, epiphenomenalism, eliminativism, and reflective choice, as well as on his thoughts about the role of consciousness more broadly. These discussions will have to wait for another day. I hope, however, to have provided here an adequate basis from which such topics can be approached. ${ }^{18}$

\footnotetext{
18 Sincere thanks are owed to the participants at the $3^{\text {rd }}$ ISNS workshop for their helpful comments and suggestions, and to Luke J. Davies for comments on an earlier version of this paper.
} 


\section{References}

\section{Nietzsche's writings}

BGE: Beyond Good and Evil. 1886/2002. Edited by Rolf-Peter Hortsmann \& Judith Norman. Translated by Judith Norman. Cambridge: Cambridge University Press.

D: $\quad$ Daybreak. 1881/1997. Edited by Maudemarie Clark and Brian Leiter. Translated by R.J. Hollingdale. Cambridge: Cambridge University Press, 1997.

GS: $\quad$ The Gay Science. 1882/2001. Edited by Bernard Williams. Translated by Josefine Nauckhoff \& Adrian Del Caro. Cambridge: Cambridge University Press.

HAH: Human, All Too Human. 1878/1986. Translated by R.J. Hollingdale. Cambridge: Cambridge University Press.

TI: $\quad$ The Twilight of the Idols. 1889/1968. Translated by R.J. Hollingdale. London: Penguin.

TL: $\quad$ On Truth and Lies in the Extra-Moral Sense. 1873/2009. In Writings form the Early Notebooks. Edited by Raymond Geuss \& Alexander Nehemas. Translated by Ladislaus Löb. Cambridge: Cambridge University Press.

Z: Thus Spake Zarathustra. 1883-91/1950. Translated by A. Tille. London: Everyman.

eKGWB: Digitale Kritische Gesamtausgabe Werke und Briefe. Edited by Giorgio Colli \& Mazzino Montinari. Accessed at http://www.nietzschesource.org/\#eKGWB.

\section{Other works}

Bermúdez, José Luis. 2003. Thinking without Words. Oxford: Oxford University Press.

— 2005. Philosophy of Psychology: A Contemporary Introduction. New York: Routledge.

Carruthers, Peter. 1996. Language, Thought, and Consciousness. Cambridge: Cambridge University Press.

Clark, Andy. 1996. "Dealing in Futures: Folk Psychology and the Role of Representations in Cognitive Science." In The Churchlands and Their Critics, edited by Robert N. McCauley, 86-103. Oxford: Blackwell.

Constâncio, João. 2011. “On Consciousness: Nietzsche's Departure from Schopenhauer." Nietssche-Studien 40: 1-42.

Damasio, Antonio. 1994. Descartes' Error. London: Vintage.

Doyle, Tsarina. 2011. "Nietzsche, Consciousness, and Human Agency." Idealistic Studies 21: 11-30.

Fowles, Christopher. Forthcoming. "The Heart of Flesh: Nietzsche on Affects and the Interpretation of the Body." Journal of the History of Philosophy.

Gauker, Christopher. 1994. Thinking Out Loud: An Essay on the Relation between Thought and Language. Princeton: Princeton University Press.

Gibson, J.J. 1977. "The Theory of Affordances." In Perceiving, Acting, and Knowing: Towards an Ecological Psychology, edited by John Bransford \& Robert Shaw, 67-82. Hillsdale, NJ: Lawrence Erlbaum. 
— 1979. The Ecological Approach to Visual Perception. Boston: Houghton Mifflin.

Helmholtz, Hermann von. 1867. Handbuch der physiologischen Optik. Leipzig: Leopold Voss.

Katsafanas, Paul. 2005. "Nietzsche's Theory of Mind: Consciousness and Conceptualization." European Journal of Philosophy 13 (1): 1-31.

— 2013. "Nietzsche's Philosophical Psychology." In Oxford Handbook of Nietəsche, edited by Ken Gemes \& John Richardson, 727-752. Oxford: Oxford University Press.

—2016. The Nietsschean Self: Moral Psychology, Agency, and the Unconscious. Oxford: Oxford University Press.

Leibniz, Gottfried Wilhelm. 1768/1981. New Essays on Human Understanding. Translated by Peter Remnant and Jonathan Bennett. Cambridge: Cambridge University Press.

Papineau, David. 2006. "Phenomenal and Perceptual Concepts." In Phenomenal Concepts and Phenomenal Knowledge: New Essays on Consciousness and Physicalism, edited by Torin Andrew Alter \& Sven Walter, 111-144. Oxford: Oxford University Press.

Riccardi, Mattia. Forthcoming. "Nietzsche on the Superficiality of Consciousness." In Nietəsche on Consciousness and the Embodied Mind, edited by Manuel Dries. Berlin: De Gruyter.

— 2015. "Nietzsche's Pluralism about Consciousness." British Journal for the History of Philosophy 24 (1): 132-154.

Rosenthal, David. 2005. Consciousness and Mind. Oxford: Clarendon Press, Oxford University Press. Ryle, Gilbert. 1949. The Concept of Mind. London: Hutchinson. 